\title{
Measuring Microhabitat Temperature in Arboreal Primates: A Comparison of On-Animal and Stationary Approaches
}

\author{
Cynthia L. Thompson ${ }^{1}$ • Susan H. Williams ${ }^{2}$. \\ Kenneth E. Glander ${ }^{3}$ - Christopher J. Vinyard ${ }^{4}$
}

Received: 11 November 2015 / Accepted: 1 August 2016 /Published online: 24 October 2016

(C) Springer Science+Business Media New York 2016

\begin{abstract}
Arboreal primates actively navigate a complex thermal environment that exhibits spatial, daily, and seasonal temperature changes. Thus, temperature measurements from stationary recording devices in or near a forest likely do not reflect the thermal microenvironments that primates actually experience. To better understand the thermal variation primates encounter, we attached automated temperature loggers to anklets worn by freeranging mantled howling monkeys (Alouatta palliata) to record near-animal ambient temperatures. We compared these measures to conventional, stationary temperature measurements taken from within the forest, in nearby open fields, and at a remote weather station $38.6 \mathrm{~km}$ from the field site. We also measured temperatures across vertical forest heights and assessed the effects of wind speed, solar radiation, rain, and vapor pressure on primate subcutaneous temperatures (collected via implanted loggers). Ambient temperatures at measurement sites commonly used by researchers differed from those experienced by animals. Moreover, these differences changed between seasons, indicating dynamic shifts in thermal environment occur through space and time. Temperatures increased with height in the forest, with statistically significant, albeit low magnitude, differences between vertical
\end{abstract}

\section{Handling Editor: Eduardo Fernandez-Duque}

Electronic supplementary material The online version of this article (doi:10.1007/s10764-016-9917-x) contains supplementary material, which is available to authorized users.

Cynthia L. Thompson

thompscy@gvsu.edu

1 Department of Biomedical Sciences, Grand Valley State University, Allendale, MI 49401, USA

2 Department of Biomedical Sciences, Ohio University Heritage College of Osteopathic Medicine, Athens, OH 45701, USA

3 Department of Evolutionary Anthropology, Duke University, Durham, NC 27708, USA

4 Department of Anatomy and Neurobiology, Northeast Ohio Medical University, Rootstown, OH 44272, USA 
distances of one meter. Near-animal temperatures showed that monkeys selected relatively warmer microhabitats during nighttime temperature lows and relatively cooler microhabitats during the day. Lastly, the thermal variables wind speed, solar radiation, vapor pressure, and rain were statistically associated with primate subcutaneous temperatures. Our data indicate that the temperatures arboreal primates experience are not well reflected by stationary devices. Attaching automated temperature loggers to animals provides a useful tool for more directly assessing primate microhabitat use.

Keywords Behavioral thermoregulation Climate $\cdot$ Microclimate $\cdot$ Temperature measurement . Thermal environment $\cdot$ Thermoregulation

\section{Introduction}

Temperature is a pervasive environmental factor that broadly affects animal ecology, physiology, and evolution (Pörtner et al. 2006). Despite its fundamental importance, characterizing the thermal environment of arboreal and highly mobile animals such as primates can be challenging. Meaningful variability in temperature conditions can occur in primate habitats on spatial scales ranging from meters to miles and temporal scales from minutes to months (Kira and Yoda 1989; Pinker 1980; van Schaik and Pfannes 2005). Microclimatic relationships are often implicit in studies of primate thermoregulation, but are rarely tested empirically (Bicca-Marques and CalegaroMarques 1998; Donati et al. 2011; Hill 2006; Pruetz 2007). Furthermore, our inability to accurately characterize thermal microhabitats limits our understanding of the relationships between temperature and behavioral and physiological processes known to be linked to temperature, including energetics (Müller 1979; Terrien et al. 2011), feeding behavior (Agetsuma 1995; Nowack et al. 2013), activity patterns (Baoping et al. 2009; Fernandez-Duque 2003; Hanya 2004; Harrison 1985; Hill 2006), reproduction (Beehner et al. 2006; Hill et al. 2000; Ohsawa and Dunbar 1984), and social behavior (Chiarello 1995; McFarland et al. 2015; Nowack et al. 2013).

The spatial and temporal heterogeneity of thermal conditions in a forest provides a range of microhabitats animals may exploit. For instance, temperature can vary with canopy height (Kira and Yoda 1989). Furthermore, foliage may create a barrier that provides cooler, shaded microhabitats below the forest cover yet warmer microhabitats above the canopy during exposure to direct sunlight (Pinker 1980). The density of tree cover can additionally impact perceived thermal variables such as wind and precipitation. Habitats also undergo daily variation as temperatures typically rise throughout much of the day and fall at night. While each of these factors may individually impact animal behavior and physiology, there can also be a dynamic interaction between spatial heterogeneity in temperatures and daily thermal variation. For instance, the top of the forest canopy should be warmer in the mid-day sun. However, loss of heat to the atmosphere after dark can cause this microhabitat to become cooler at night and in the early morning (Fetcher et al. 1985). Likewise, microhabitats below dense foliage will be cool and shaded during the day, but retain heat and become relatively warmer at night (Barradas and Fanjul 1986). Animals exploit this complexity by actively moving throughout this thermally heterogeneous environment, continually experiencing different thermal conditions (Mabille et al. 2011). 
Given this thermal complexity, conventional stationary temperature recording devices or weather stations may not accurately characterize the thermal microhabitats of arboreal primates moving throughout a forest. In some cases, researchers have recorded temperature in the home range of study animals (Campos and Fedigan 2009; Hanya et al. 2007). However, particularly for large research sites, temperature monitoring often occurs at more convenient locations such as a researcher's camp clearing or park headquarters (Baoping et al. 2009; Beehner et al. 2006). Several studies have used weather data from off-site locations, such as the nearest city or airport where temperatures are automatically recorded and publically available (De la Fuente et al. 2014; Fedigan and Griffin 1996; McFarland et al. 2014; Raichlen et al. 2010; Zajicek et al. 2000). While pragmatic and potentially useful for larger scale comparisons (e.g., between years or different geographic locations), these data likely do not reflect conditions at the research site, let alone the thermal microhabitats experienced by the animals.

Differences in microhabitat temperature have the potential to meaningfully impact primate thermoregulation. Non-human primate thermoneutral zones (the range of ambient temperatures at which animals do not expend additional energy on thermoregulation) have a breadth of $3-10{ }^{\circ} \mathrm{C}$ (Dausmann et al. 2009; Johnson and Elizondo 1979; Müller 1979; Stitt and Hardy 1971; summarized in Thompson et al. 2014). While the variables dictating thermoneutrality in wild primates are more complex than just temperature, this range generally indicates that a difference of only a few degrees could impact animals' behavior and physiology. Combined with growing evidence that temperature differences between thermal microhabitats are important for understanding mammalian biology (Briscoe et al. 2014; Hetem et al. 2007; Limberger et al. 1986; Pruetz 2007; Shi et al. 2015), this implies that more accurate methods to evaluate primate thermal environments are needed.

We attached temperature measurement devices directly to an arboreal primate, the mantled howling monkey (Alouatta palliata), to compare near-animal ambient temperatures reflecting the thermal microhabitat of the animal with stationary techniques conventionally used for measuring temperature in primatology. With the ultimate goal of informing decisions regarding temperature measurement techniques for primatological studies, we used these data to address four aims:

Aim 1 We first assessed whether near-animal ambient temperatures were influenced by the animal's body heat in proximity to loggers. If body heat impacts temperatures recorded by near-animal ambient loggers, then a) subcutaneous temperatures should be more closely related to near-animal ambient temperatures than measurements at other locations. Given that both ambient and mammalian body temperatures should increase during the day and decrease at night, correlations should be positive (Refinetti 2010). However, we would predict a relatively larger impact of subcutaneous temperatures on near-animal ambient compared to temperatures measured at other locations. b) We would also predict similar correlations between subcutaneous and near-animal ambient temperatures during both daytime and nighttime. Conversely, different relationships between night and day would suggest that these two temperatures are free to independently vary (i.e., subcutaneous temperature does not dictate the near-animal ambient 
temperature recorded). c) Changes in subcutaneous temperatures should precede changes in near-animal ambient temperature rather than vice versa. d) Postures with limbs near the body place loggers in closer proximity to the major heat-generating mass of the body (i.e., trunk and other limbs) and increase the likelihood loggers will contact the skin (loggers most often hung loosely from an anklet). To provide a scale for this effect, for smaller bodied primates $(<2 \mathrm{~kg})$ loggers on the skin approximate core body temperatures (Dausmann 2005). As such, if body heat impacts near-animal ambient loggers, then when animals employ postures bringing the limbs close to the body, nearanimal ambient temperatures should be more similar to subcutaneous temperatures than for postures in which limbs are further from the body. Conversely, if there is not a marked impact of body heat on near-animal ambient loggers, we would predict temperatures from these loggers to reflect the ambient temperatures at which animals employ these postures. This would be the opposite pattern, where postures with limbs close to the body are displayed at cooler near-animal ambient temperatures and postures with extended limbs are used at warmer ambient temperatures. e) If body heat impacts loggers, then we also predict greater variation in near-animal ambient temperatures when animals assume postures that increase the opportunity for contact between the logger and the body.

Aim 2 We determined the magnitude of temperature differences among measurement locations (i.e., on-animal, forests, open fields, and remote weather stations) and examined the impact of daily and seasonal shifts on potential differences among recording locations. To assess spatial heterogeneity further, we also determined whether ambient temperatures vary throughout the height of the canopy.

Aim 3 Since thermal variables beyond temperature can also impact an animal's perceived thermal environment (Hill et al. 2004), we assessed the relative influence of vapor pressure, solar radiation, rain, and wind on subcutaneous temperatures of howlers.

Aim 4 We determined whether animals selectively navigate thermal microhabitats. If animals seek cooler microhabitats during ambient heat and warmer microhabitats during cool ambient conditions, then the regression slope of near-animal ambient conditions to other measurements should be $<1$ (Hetem et al. 2007). Similarly, at the warmest and coolest ambient temperatures, simultaneously collected near-animal ambient temperatures should be cooler and warmer, respectively.

\section{Methods}

\section{Data Collection}

Site Information We collected data on mantled howling monkeys at Hacienda La Pacifica, a private 1980 ha ranch located in the Province of Guanacaste, Costa Rica $\left(10^{\circ} 28^{\prime} \mathrm{N}, 85^{\circ} 07^{\prime} \mathrm{W}\right)$. La Pacifica is in the lowland tropical dry forest life zone and comprised of secondary growth, seasonally dry deciduous forest (Holdridge 1967). Mantled howlers at La Pacifica inhabit both riparian forests and more seasonal dry, 
non-river forest patches (Glander 1975; Glander and Nisbett 1996). Based on weather monitoring from 1971 to 2006 (collected with a Davis Weatherlink Station in an open field), daily temperatures during the dry season (November-April) range from 22.5$34.1{ }^{\circ} \mathrm{C}\left(\bar{x}=28.1{ }^{\circ} \mathrm{C}\right)$ with $42 \%$ mean relative humidity. Wet season (May-October) temperatures range from $21.8-33.8^{\circ} \mathrm{C}\left(\bar{x}=26.1^{\circ} \mathrm{C}\right)$ with $94 \%$ mean relative humidity. Mean annual precipitation is $1368 \mathrm{~mm}$ (range: $831-2701$ ), with heavy rains occurring during the wet season and little precipitation during the dry season (Daubenmire 1972; Glander unpubl. data).

Environmental Temperatures We collected environmental temperature data during the dry $(2 / 28-3 / 15)$ and wet (7/11-7/23) seasons of 2014 at multiple locations: 1$)$ nearanimal ambient; 2) within the forest inhabited by howlers; 3 ) in an open field; 4) at an on-site weather station located in a separate open field (wet season only); 5) a remote weather monitoring station $38.6 \mathrm{~km}$ away from the field site; and 6) vertical canopy strata in the forest inhabited by howlers (1-13 m) (Fig. 1). The total data set consisted of 13,124 temperature measurements collected through instantaneous sampling (Martin and Bateson 1993) across the different locations, cumulatively representing 18 days in the dry season $(N=6417$ instantaneous temperature samples) and 14 days in the wet season $(N=6680)$ and covering both morning $(0: 00-11: 59 \mathrm{~h}: N=6505)$ and afternoon (12:00-23:59 h: $N=6619)$. With the exception of the remote location, all measurements were taken within a $1.0 \mathrm{~km}^{2}$ area at the study site (Fig. 1). Only daily minimum and maximum temperatures were available from the remote location. Otherwise, we sampled temperatures concurrently at all temperature measurement locations at synchronized $10 \mathrm{~min}$ intervals. This sampling rate has the ability to capture short-

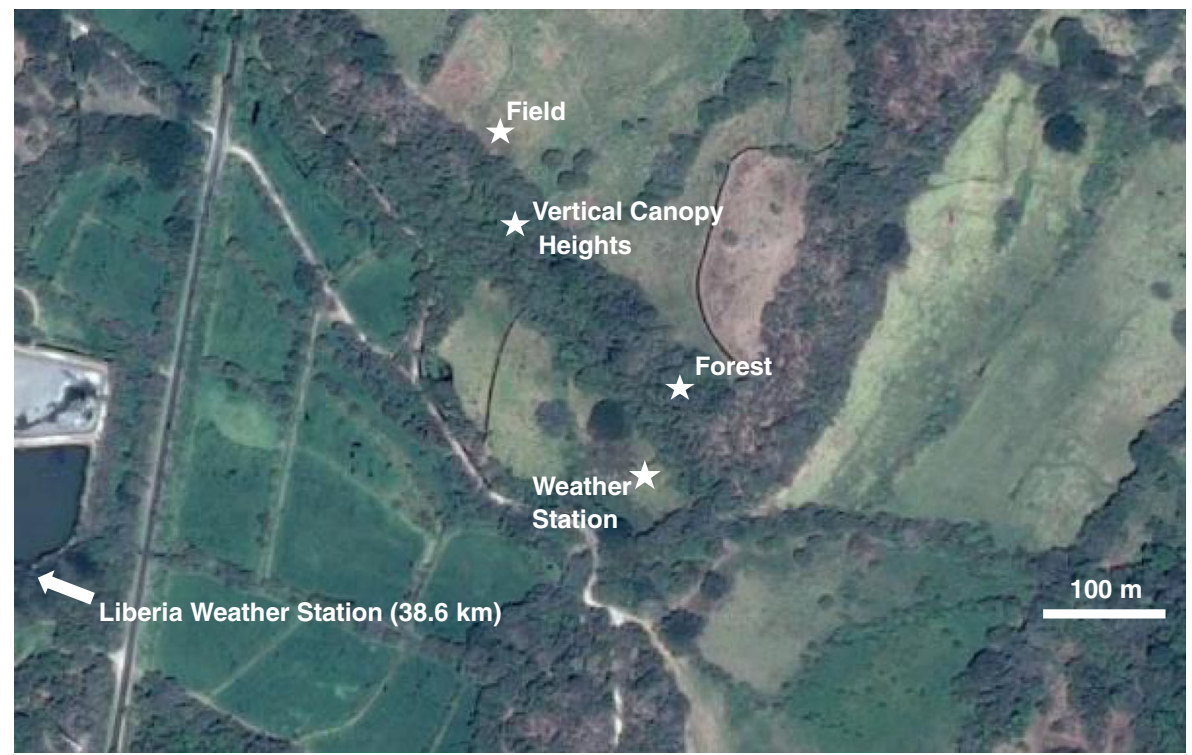

Fig. 1 Map of the study area at Hacienda La Pacifica, Costa Rica with temperature recording locations noted (aerial photo taken in 2010). 
term temperature changes animals experience as they move through a thermally heterogeneous environment. Details of each measurement location are provided below.

We recorded near-animal ambient temperatures by attaching an automated temperature data logger (iButton: Maxim Integrated Products; $17 \mathrm{~mm} \times 6 \mathrm{~mm}$; $3.3 \mathrm{~g}$ ) directly to an anklet made of metal chain link. This logger placement has the advantage of recording ambient temperatures at the animal's exact location in space and time. Loggers were certified as accurate to $\pm 0.5^{\circ} \mathrm{C}$ by the manufacturer and post-production between-logger precision has been reported to be \pm 0.4 ${ }^{\circ} \mathrm{C}$ (Johnson et al. 2005). Testing of our own loggers after data collection revealed a mean pairwise difference between loggers (placed in the same location) of $0.02{ }^{\circ} \mathrm{C}(\mathrm{SD}=0.68 ; N=129$ measurements from three loggers at 20.3$34.3{ }^{\circ} \mathrm{C}$ ). These accuracy and precision measurements should be taken into account when assessing the magnitude of effect sizes of results. Measurement error notwithstanding, we set loggers to record at a resolution of $0.0625{ }^{\circ} \mathrm{C}$. We placed data loggers attached to animals inside a thin steel casing with reflective coating on the outside, which hung freely from its attachment, and was not directly held against skin. Loggers in this metal casing did not produce statistically significant differences in temperatures than those in mesh and plastic bags (see methods below) $\left(\bar{x}\right.$ pairwise difference $=-0.37-0.39{ }^{\circ} \mathrm{C}$, ANOVA: $F_{(2,45)}=$ $0.61, P=0.54)$ when recording in the same location.

Data stored onboard the iButtons were manually downloaded after collection. We captured and recaptured animals following Glander et al. (1991) to attach and recover loggers, respectively. We captured four adult animals $(N=2$ females, $N=2$ males). Loggers remained on animals for $12-16$ days $(\bar{x}=13.3)$. For analysis, we used the mean of simultaneously collected near-animal ambient temperatures over all animals to avoid pseudoreplication. No lapses in battery life of iButtons occurred and data were effectively logged for the full period in all deployments.

We recorded field and forest temperatures using iButtons placed in a clear plastic bag nailed $\sim 1 \mathrm{~m}$ off the ground on either a fence post (field measurement) or tree (forest measurements). We took field measurements in an open clearing immediately neighboring (within $15 \mathrm{~m}$ ) the home range of animals (Fig. 1). We recorded forest temperatures within the home range of monitored animals which consisted predominately of secondary growth, with a few primary growth trees. The extent of canopy density varied within the animals' home range (Fig. 1). We recorded both field and forest measurements with a single iButton in each location.

We deployed an on-site weather station (HOBO U30, Onset Computer Corporation, Bourne, MA) in a clearing adjacent to (within $20 \mathrm{~m}$ ) the home range of monitored animals (Fig. 1). The station measured air temperature with a solar radiation shield, rainfall, solar radiation, and wind speed. We also used relative humidity measurements from the weather station to calculate vapor pressure as: relative humidity $/ 6.11 \times 10^{\left(\frac{7.5 \times \text { temperature }}{237.3+\text { temperaure }}\right)}$. Temperature accuracy is stated by the manufacturer to be $\pm 0.2{ }^{\circ} \mathrm{C}$, measured at a resolution of $0.03{ }^{\circ} \mathrm{C}$.

For the remote location, we accessed public temperature data from the US National Oceanic and Atmospheric Administration's (NOAA) National Climatic Data Center. We obtained data from the nearest temperature monitoring station to the field site, 
collected in Liberia, Costa Rica, located $38.6 \mathrm{~km}$ away (straight-line distance). Available data from this location consisted only of daily minimum and maximum temperatures. As such, we calculated daily minimum and maximum temperatures (for days with $>18$ h of recording) for the instantaneous data from near-animal ambient loggers, forest, field, and the on-site weather station for comparison.

To characterize temperature variation throughout the height of canopy strata, we attached iButtons enclosed in a mesh bag to a rope in $1 \mathrm{~m}$ increments up to $13 \mathrm{~m}$ off the ground. We suspended the rope from a tree in a section of forest within the animals' home range (Fig. 1). While loggers did not reach the top of the forest canopy, the highest loggers did receive direct sunlight at specific points during the day.

Subcutaneous Temperatures We also recorded subcutaneous temperatures of animals by implanting a sterilized iButton directly under the skin between the shoulder blades while animals were under general anesthesia (Lovegrove 2009; Thompson et al. 2014). We implanted and extracted subcutaneous loggers at the same time near-animal loggers were attached, but only during the wet season. We waited $>14 \mathrm{~h}$ postcapture to collect subcutaneous temperatures to avoid thermal effects of tiletamine-based anesthesia (Lopez et al. 2002). For analysis, we used means of simultaneously collected subcutaneous temperatures over all animals to avoid pseudoreplication.

\section{Data Analysis}

Animal $\times$ Ambient Temperature Interactions To assess whether body heat impacted on-animal loggers, we conducted Pearson's correlations between near-animal ambient loggers and subcutaneous temperatures (using means from simultaneously collected points across all individuals), as well as with all other pairwise combinations of measurement location. Additionally, we tested the Pearson's correlation between subcutaneous and near-animal ambient measures separately for nighttime (18:01-05:59 h) and daytime (06:00-18:00 h). We also conducted a multiple linear regression predicting near-animal ambient temperatures from subcutaneous and forest temperatures, to more specifically discriminate between potential effects of body heat relative to those of ambient temperature. Lastly, we assessed cross-correlations (lags $\pm 70 \mathrm{~min}$ ) between subcutaneous and near-animal ambient temperatures for each day of data per animal ( $N=50$ days) to determine if changes in subcutaneous temperature precede changes in near-animal ambient temperature.

Next, we analyzed the body posture displayed by animals in relation to recorded temperature. We coded body posture into five ordinal categories, from greatest to least proximity of loggers to the major body mass of the individual: curled - back flexed, all limbs and tail in a ball; sitting — back flexed, body on lower limbs, ventrum exposed; lying — back extended, all or three limbs near body; spread — back extended, one or two limbs near body; extended-back extended, no limbs near body (Bicca-Marques and Calegaro-Marques 1998). We recorded posture using instantaneous sampling for four animals during daylight hours at 10 min intervals synchronized with temperature recording ( $N=1821$ instantaneous temperature points). We tested differences in nearanimal ambient temperatures between postures using Jonckheere-Terpstra test of ordered alternatives, done separately for each individual. We also calculated the 
difference between subcutaneous and near-animal ambient loggers $(N=1698$ instantaneous temperature points) and tested for differences between postures for each individual using Jonckheere-Terpstra tests. Lastly, to assess variation in near-animal ambient temperatures across postures we calculated the temperature difference between sequential 10 min samples in a posture $(N=1493)$ and report standard deviations and ranges.

Temperature Measurement Location To determine if temperatures varied across measurement locations, we performed repeated measures ANOVAs separately for the wet and dry season. All temperatures in a single analysis were collected at identical points in time at all locations (i.e., there were no missing values in analyses), ensuring direct comparability. The wet season analysis compared near-animal ambient, forest, field, and weather station locations; the dry season included all of these locations except the weather station. The models included time of day as a covariate. We also tested for an interaction between measurement location and time of day. Pairwise Bonferroni post hoc tests on estimated marginal means (EMM) were used to assess differences between specific measurement locations ( $\alpha=0.05$; Bonferroni adjustment applied to $P$-values). We similarly analyzed daily maximum and minimum temperatures from near-animal ambient, field, forest, on-site weather station (wet season only), and the remote location (NOAA) with repeated measures ANOVAs and Bonferroni post hoc testing.

Height in Canopy We also conducted repeated measures ANOVAs for instantaneous temperature data at meter increments (to account for non-independence of temperatures recorded simultaneously at each canopy height) from the ground to $13 \mathrm{~m}$ in the canopy to assess whether temperature varied with canopy height. To assess if potential differences in height may be due to more sunlight near the top of the canopy, we conducted these tests separately for daytime (06:00-18:00 h) and nighttime (18:0105:59 h). We included the variable season (wet versus dry) in the models as a betweensubjects factor. We used pairwise Bonferroni post hoc tests to assess temperature differences at $1 \mathrm{~m}$ scales within the canopy $(\alpha=0.05)$.

Perceived Thermal Environment We conducted a multivariate regression to investigate which thermal variables influence subcutaneous temperatures, collected in the wet season. We considered all possible models using the following variables (collected at the same location via the on-site weather station), known to have potential impacts on mammalian thermoregulation (Hill et al. 2004): air temperature, wind speed, solar radiation, rain, and vapor pressure. We used Akaike's Information Criterion (AIC) to determine the top three explanatory models for subcutaneous temperatures and used values from these models to assess the relative effects of different thermal variables.

Microhabitat Selection by Howlers To test the prediction that animals seek cooler microhabitats during ambient heat and warmer microhabitats during cool ambient conditions, we performed bivariate linear regressions between near-animal ambient temperatures and field, forest, and weather station temperatures. Similarly, using the 25 $\%$ coolest and $25 \%$ warmest data points from forest and field measurements, we compared the corresponding near-animal ambient temperature via paired $t$-test. Tests were assessed at $\alpha=0.05$. 


\section{Ethical Note}

All procedures were approved by the Northeast Ohio Medical University, Duke University, Ohio University, and Grand Valley State University Institutional Animal Care and Use Committees. This research adhered to Costa Rican legal requirements. Research permits were obtained through the Organization for Tropical Studies and Ministerio del Ambiente y Energía. Permission was provided by Hacienda La Pacifica's Board of Directors.

\section{Results}

\section{Animal $\times$ Ambient Temperature Interactions}

Near-animal ambient temperatures were less closely correlated with subcutaneous temperatures than with all other on-site measures of ambient temperature (forest, field, and weather station) (Table I). Likewise, the correlation between subcutaneous and near-animal ambient temperature was lower than between subcutaneous temperatures and forest or weather station temperatures (but not field) (Table I), which fails to support the hypothesis that near-animal ambient temperatures were significantly impacted by body heat. Daytime correlations between subcutaneous and near-animal ambient temperatures were high (Pearson's correlation: $r=0.71, P<0.001, N=811$ ), as both subcutaneous and ambient temperature rose during the day. However, nighttime correlations were substantially lower $(r=0.28, P<0.001, N=863)$, with subcutaneous temperatures leveling off at biological minimums while ambient temperatures continued to fall throughout the night. Similar to these correlations, multiple regression models show a positive relationship with near-animal ambient temperature (standardized $\beta=0.20, P<0.001$ ), with forest temperatures showing a comparatively larger effect (standardized $\beta=0.67, P<0.001$ ). Yet, subcutaneous temperatures uniquely explained only $1.99 \%$ of variation in near-animal ambient temperatures (semipartial correlation), compared to $21.62 \%$ uniquely explained by forest temperatures. Lastly, cross correlations show no systematic evidence that changes in subcutaneous temperatures preceded changes in near-animal ambient temperatures. Of 50 days, 46 showed statistically significant cross correlations. However, for the majority of significant days (43\%;N=20), changes in near-animal ambient temperatures preceded changes in

Table I Pearson's correlation coefficients (top diagonal) and pairwise sample size overlap (bottom diagonal) between temperature measurement locations for mantled howling monkeys at La Pacifica, Costa Rica in 2014

\begin{tabular}{lcccccc}
\hline $\begin{array}{l}\text { Measurement } \\
\text { location }\end{array}$ & Subcutaneous & $\begin{array}{c}\text { Near-animal } \\
\text { ambient }\end{array}$ & Forest & Field & $\begin{array}{c}\text { Weather } \\
\text { station }\end{array}$ & $\begin{array}{c}\text { Remote site } \\
\text { (days) }\end{array}$ \\
\hline Subcutaneous & $\mathbf{1 6 7 4}$ & 0.68 & 0.72 & 0.66 & 0.71 & $0.49,0.30$ \\
Near-animal ambient & 1674 & $\mathbf{3 8 1 3}$ & 0.76 & 0.69 & 0.78 & $0.46,0.49$ \\
Forest & 1674 & 3813 & $\mathbf{3 8 1 3}$ & 0.88 & 0.97 & $0.61,0.42$ \\
Field & 1674 & 3813 & 3813 & $\mathbf{3 8 1 3}$ & 0.95 & $0.56,-0.21$ \\
Weather station & 1670 & 1670 & 1670 & 1670 & $\mathbf{1 6 7 0}$ & $0.26,<0.01$ \\
Remote site (days) & 11 & 24 & 24 & 24 & 11 & $\mathbf{2 4}$ \\
\hline
\end{tabular}

Remote site correlations $=$ min, $\max$ daily temperatures. For remote site, sample sizes are number of days; all other measurements are instantaneous measurements throughout the day

Bold and gray shading indicate total sample size for a measurement location 
subcutaneous temperatures; $35 \%(N=16)$ of days had no lag. Subcutaneous temperatures preceded near-animal ambient for only $22 \%(N=10)$ of days; of these, one day $(2 \%)$ had a negative correlation, the opposite direction than predicted if body heat were impacting loggers.

For the posture analysis, the observed pattern was the opposite of that predicted if body heat impacted loggers, with all animals exhibiting a statistically significant decrease in near-animal ambient temperature as postures with limbs closer to the body were used (Jonckheere-Terpstra tests: animal 1: $z=9.7$, $P<0.001, N=543 ; 2: z=9.5, P<0.001, N=392 ; 3: z=6.1, P<0.001, N=$ 443; $4: z=5.0, P<0.001, N=443$ ) (Table II). Likewise, the difference between subcutaneous and near-animal ambient loggers was greater, rather than less, when animals used postures with limbs closer to the body (animal 1: $z=-5.7$, $P<0.001, N=542 ; 2: z=-5.8, P<0.001, N=392 ; 3: z=-2.1, P=0.034, N=$ 321) (Table II), with one individual showing no relationship between posture and temperature $(z=-1.5, P=0.13, N=443)$. There was not a consistent relationship between posture and variation in temperature change between sequential 10 min samples in that posture (Table II).

\section{Temperature Measurement Location}

There were statistically significant differences in temperature between measurement locations in both the dry season (repeated measures ANOVA: $F_{(1.2,2513.3)}=$ 151.6, $P<0.001)$ and wet season $\left(F_{(1.1,1841.6)}=193.7, P<0.001\right)$. Measurement location explained $6.6 \%$ of variation in temperature in the dry season and 10.4 $\%$ in the wet season. Post hoc tests on EMMs (accounting for time of day) showed statistically significant differences in temperature between all possible

Table II Temperature and temperature variation of mantled howling monkeys in different postures at La Pacifica, Costa Rica, 2014

\begin{tabular}{lllll}
\hline Posture $^{\mathrm{a}}$ & $\begin{array}{l}\text { Mean }( \pm \mathrm{SEM}) \\
\text { near-animal } \\
\text { ambient } \\
\text { temperature }\left({ }^{\circ} \mathrm{C}\right)\end{array}$ & $\begin{array}{l}\text { Mean difference } \\
( \pm \mathrm{SEM}) \text { between } \\
\text { near-animal ambient } \\
\text { and subcutaneous } \\
\left({ }^{\circ} \mathrm{C}\right)\end{array}$ & $\begin{array}{l}\text { Standard deviation } \\
\text { of temperature } \\
\text { difference between } \\
10 \text { min samples }\end{array}$ & $\begin{array}{l}\text { Total range } \\
\text { of temperature } \\
\text { difference in } \\
10 \text { min samples } \\
\left({ }^{\circ} \mathrm{C}\right)\end{array}$ \\
\hline Curled & $30.4(0.3)$ & $6.2(0.2)$ & 1.2 & 7.3 \\
Sitting & $31.8(0.2)$ & $5.8(0.1)$ & 1.3 & 7.9 \\
Lying & $32.5(0.2)$ & $5.2(0.2)$ & 1.3 & 7.5 \\
Spread & $33.2(0.4)$ & $5.2(0.4)$ & 1.4 & 6.5 \\
Extended & $33.4(0.3)$ & $5.3(0.2)$ & 1.2 & 6.5 \\
\hline
\end{tabular}

Statistics are pooled values across individual animals' values $(N=4)$, by each posture

${ }^{a}$ Postures follow Bicca-Marques and Calegaro-Marques (1998). From greatest to least proximity of logger to the major body mass of animal: curled — back flexed, all limbs and tail in a ball; sitting - back flexed, body on lower limbs, ventrum exposed; lying — back extended, all or three limbs near body; spread — back extended, one or two limbs near body; extended — back extended, no limbs near body

${ }^{\mathrm{b}}$ Range represents the full spectrum of positive and negative changes in temperature (e.g., $-5{ }^{\circ} \mathrm{C}$ through +5 ${ }^{\circ} \mathrm{C}$ changes) 
pairwise combinations of measurement locations (all tests: $P<0.001$ ), with the exception of the near-animal ambient and field comparison $(P \approx 1.0$, both seasons). The magnitude of statistically significant temperature differences between locations ranged from $2.3-3.0^{\circ} \mathrm{C}$ (Fig. 2). For comparison, in this study the mean difference in near-animal ambient temperatures between daytime and nighttime samples was $2.2{ }^{\circ} \mathrm{C}$.

All locations showed daily patterns with higher daytime than nighttime temperatures, although some locations had more pronounced daily fluctuations (Fig. 3). There was a statistically significant interaction between time of day and measurement location during the dry season (repeated measures ANOVA: $\left.F_{(1.2,2513.3)}=8.9, P=0.002\right)$, but not the wet season $\left(F_{(1.1,1841.6)}=0.6, P=\right.$ $0.450)$. In both seasons this interaction explained $<1 \%$ of variation in temperatures, suggesting a weak effect. Still, field values were generally lower than other locations at night, but had the highest temperatures during the day (Figs. 3a, b and $4 \mathrm{a}-\mathrm{d}$ ). Similarly, forest temperatures were higher than those obtained at other measurement locations at night, but showed the lowest daytime temperatures, reflecting a dynamic interplay between spatial and temporal temperature heterogeneity (Fig. 3a, b).

There were statistically significant differences between temperature locations for both daily minimum (repeated measures ANOVA: dry: $F_{(1.5,16.9)}=73.0$, $P<0.001$; wet: $\left.F_{(2.1,20.6)}=39.7, P<0.001\right)$ and maximum temperatures (dry: $F_{(1.2,13.6)}=117.7, P<0.001$; wet: $\left.F_{(1.3,12.7)}=141.8, P<0.001\right)$ (Fig. 4). Location explained a large proportion of the variance in both mean daily minimum (dry: $86.9 \%$; wet: $79.9 \%$ ) and maximum temperatures (dry: $91.5 \%$; wet: $93.4 \%$ ). For minimum daily temperatures in the dry season, all pairwise combinations of measurement location showed statistically significant differences, with the remote site being consistently lower than all other measurement locations (Bonferroni post hoc tests: $\bar{x}$ difference range $=-6.6$ to $-3.0{ }^{\circ} \mathrm{C} \pm 0.35-0.61 ; P=0.003$ to $<$ 0.001) (Fig. 4a). For wet season minimum daily temperatures, all pairwise

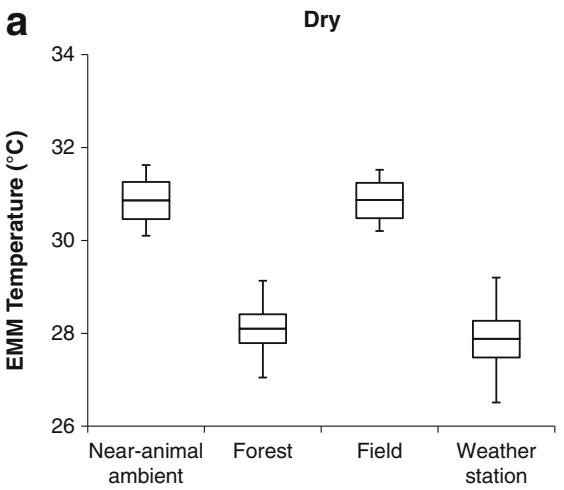

Measurement Location

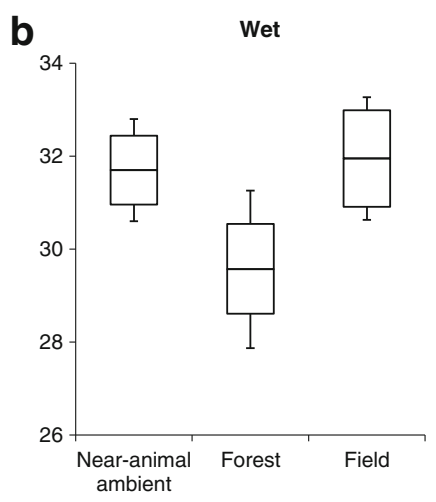

Measurement Location

Fig. 2 Estimated marginal mean (EMM) temperatures (controlling for time of day) by measurement location for instantaneous temperature points at Guanacaste, Costa Rica during the dry (a) and wet (b) season of 2014. Near-animal ambient values are from mantled howling monkeys at La Pacifica, Costa Rica. Boxes represent the median, 25th, and 75th percentiles; whiskers are percentiles \pm 1.5 interquartile ranges. 


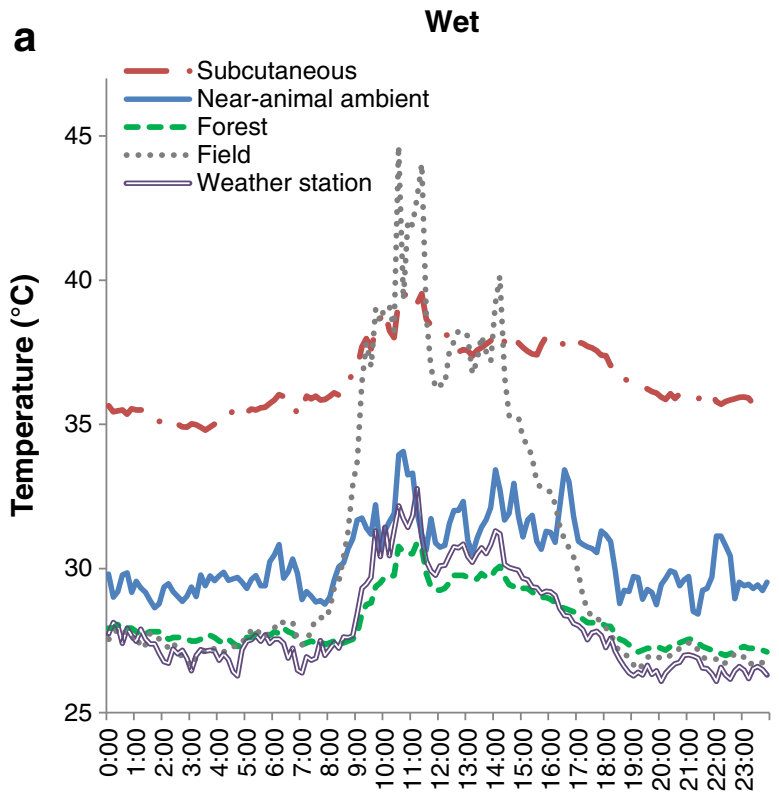

Time of Day

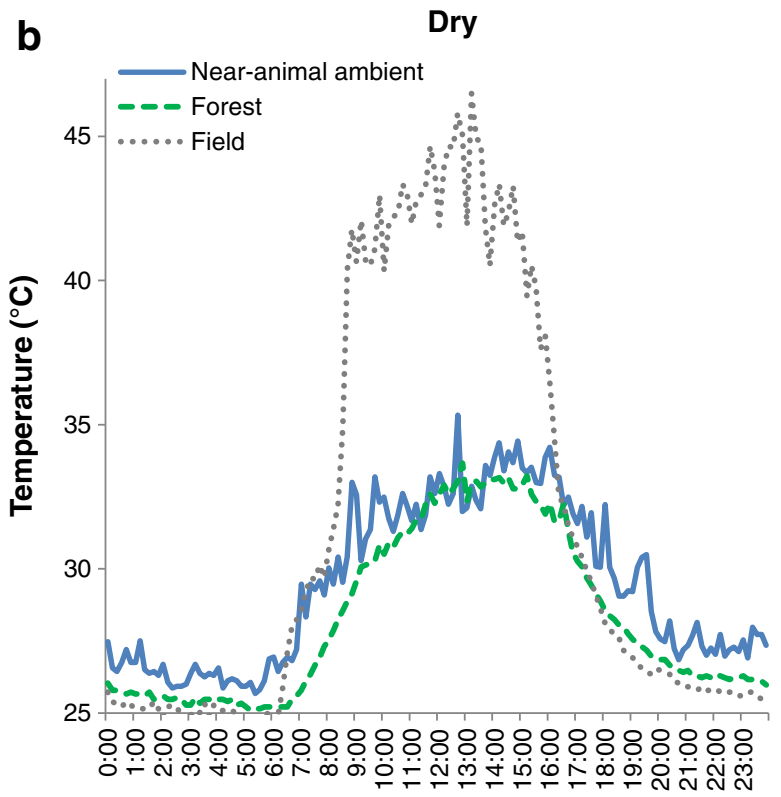

\section{Time of Day}

Fig. 3 Temperature variation from different measurement locations across time of day from instantaneous temperature data points on representative days from Guanacaste, Costa Rica during the wet (a) and dry (b) seasons of 2014. Weather station and subcutaneous temperatures were not measured in the dry season. Nearanimal ambient and subcutaneous values are means across sampled mantled howling monkeys $(N=4)$ at La Pacifica, Costa Rica. 
a

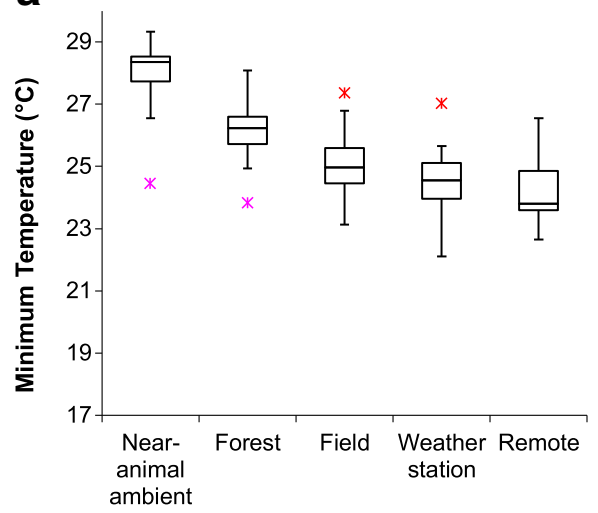

b

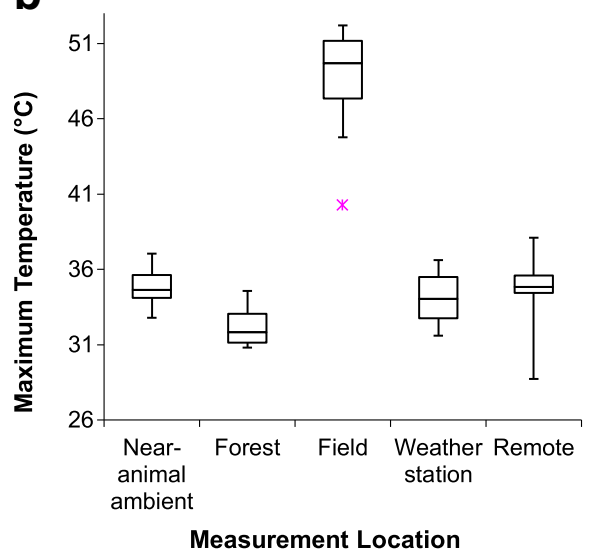

C

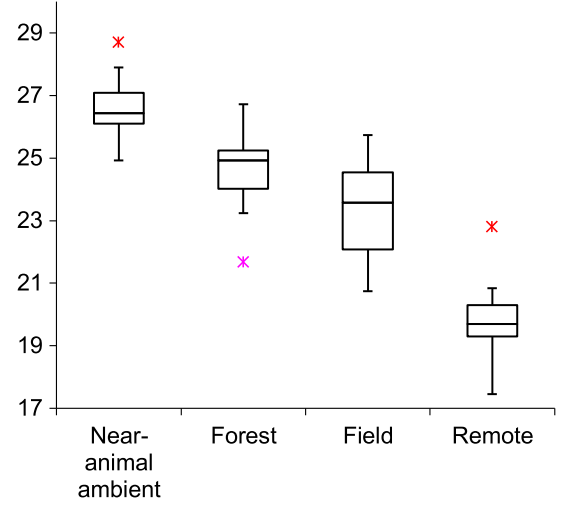

d

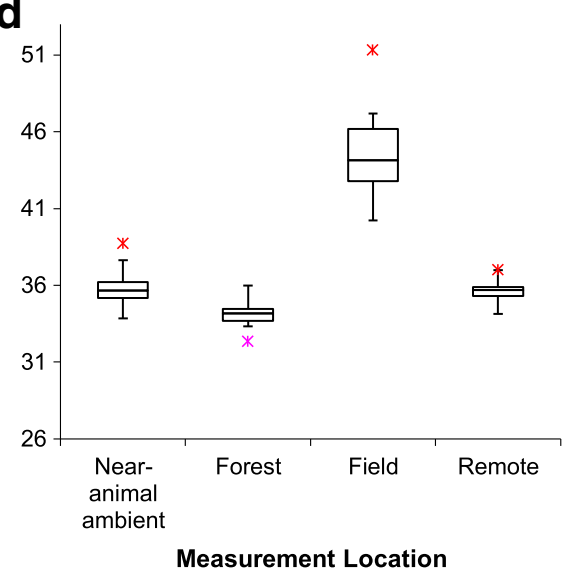

Fig. 4 Minimum and maximum daily temperature measurements from on-site and remote locations in Guanacaste, Costa Rica during the wet and dry seasons of 2014. Near-animal ambient values are from mantled howling monkeys at La Pacifica. Boxes represent the median, 25th, and 75th percentiles; whiskers are percentiles \pm 1.5 interquartile ranges. Outliers (stars) exceed 1.5 interquartile ranges above (red)/below (purple) the upper/lower quartile of data.

combinations of measurement locations statistically differed $(\bar{x}$ difference range $=$ -3.5 to $2.9{ }^{\circ} \mathrm{C} \pm 0.08-0.44 ; P=0.002$ to $\left.<0.001\right)$ with the exception of the remote to field comparison ( $\bar{x}$ difference $\left.=-1.0{ }^{\circ} \mathrm{C} \pm 0.33 ; P=0.138\right)$ and the remote to weather station comparison $\left(\bar{x}\right.$ difference $=-0.5{ }^{\circ} \mathrm{C} \pm 0.34 ; P \approx 1.0$ ) (Fig. 4c). For daily temperature maximums in the dry season, all measurement locations displayed statistically significant differences from one another $(\bar{x}$ difference range $=-10.5$ to $\left.1.5{ }^{\circ} \mathrm{C} \pm 0.27-0.88 ; P \leq 0.001\right)$ except the remote to near-animal ambient comparison $\left(\bar{x}\right.$ difference $=-0.3{ }^{\circ} \mathrm{C} \pm 0.21 ; P \approx 1.0$ ) (Fig. 4b). For wet season daily maximums, forest and field measurements showed statistically significant differences from all other locations $(\bar{x}$ difference range $=-16.9$ to $3.0^{\circ} \mathrm{C} \pm 0.31-1.3 ; P=0.002$ to $<0.001$ ), while the remote site, near-animal ambient and the weather station did not differ from each other $(\bar{x}$ difference range $=-0.1$ to $1.1{ }^{\circ} \mathrm{C} \pm 0.40-0.60 ; P \approx 1.0$ ) (Fig. $4 \mathrm{~d}$ ). 


\section{Height in Canopy}

During daytime, there were statistically significant differences in temperature between heights in the canopy (repeated measures ANOVA: $F_{(12,7709)}=516.9$, $P<0.001$ ), with temperatures increasing at greater heights (Fig. 5). Height explained $21.6 \%$ of variation in daytime temperatures whereas season explained only $5.9 \%$ of variation, with the remaining variation included in error in the model. The majority (74 of 78) of pairwise Bonferroni post hoc comparisons of canopy height temperatures had statistically significant differences $(P \leq 0.01)$, indicating that changes in height of only $1 \mathrm{~m}$ can impact the temperature animals experience (Fig. 5). While the magnitude of differences between meter intervals was low in comparison to potential between-logger measurement error $(\bar{x}$ difference $\left.=0.08{ }^{\circ} \mathrm{C}\right)($ Fig. 5), total temperature differences across the canopy exceeded measurement error estimates. Similar patterns of increasing temperatures at greater heights were obtained for nighttime samples (repeated measures
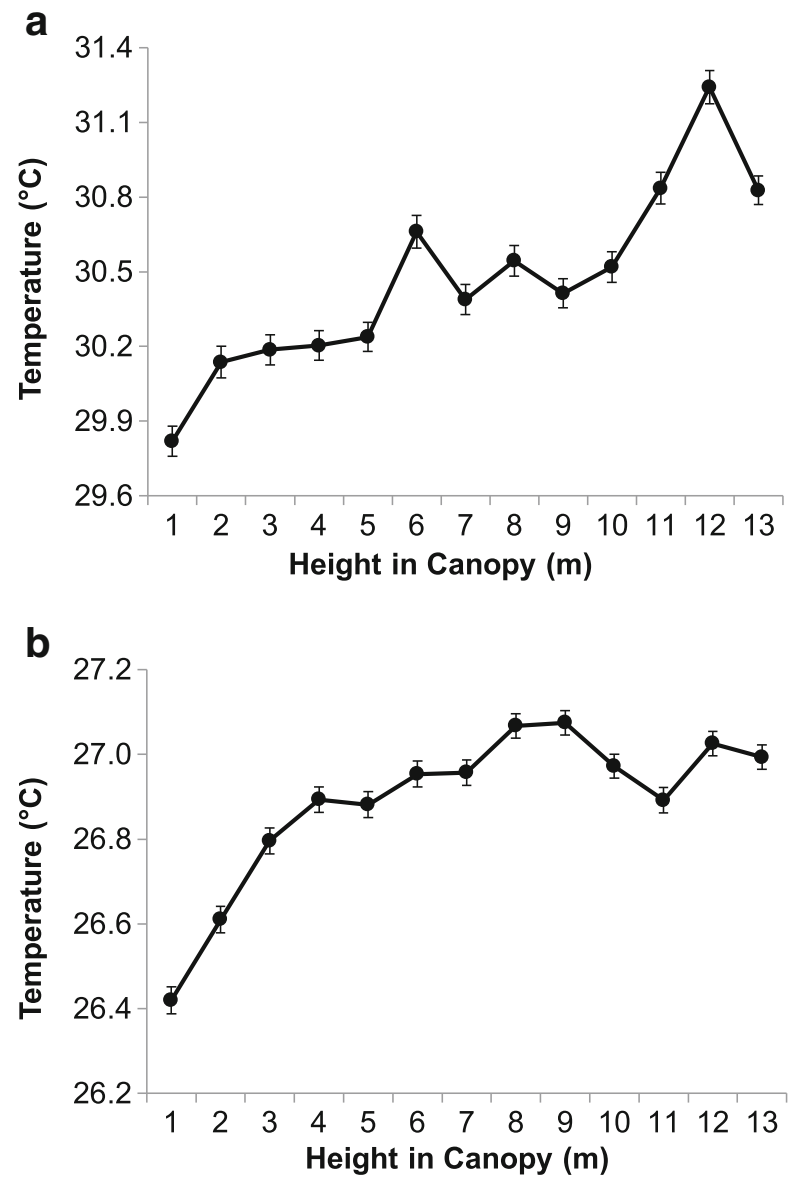

Fig. 5 Ambient temperatures over vertical heights of the forest canopy at La Pacifica, Costa Rica in 2014, during daytime (a) and nighttime (b). Error bars denote the standard error of the mean at each canopy height. 
ANOVA: $F_{(12,2942)}=3114.0, P<0.001 ; \bar{x}$ difference between subsequent $1 \mathrm{~m}$ intervals $=0.05{ }^{\circ} \mathrm{C}$ ). At night, height explained $61.7 \%$ of variation in temperatures; season explained $8.5 \%$. Overall temperature variation (pooling day and night) was consistent across heights in the canopy, with coefficients of variation for each height ranging between $9.6 \%$ and $11.1 \%(\bar{x}=10.2 \%)$.

\section{Perceived Thermal Environment}

Both temperature and other perceived thermal variables were statistically significant predictors of subcutaneous body temperature in howlers (Table III). Based on $\mathrm{AIC}$, the best fit regression model included all environmental variables, while the second and third best models included all variables except rain and vapor pressure, respectively (Table III). As indicated by standardized slopes ( $\beta$ : Table III), changes in air temperature had the strongest impact on subcutaneous temperatures, followed by solar radiation. The remaining thermal variables, while variably statistically significant in the model, had very low slopes, indicating they were associated with only small changes in subcutaneous temperature (Table III). However, all three top models explained 51.2-51.0 \% of variation in subcutaneous temperatures, indicating that the collective influence of these variables on animals' subcutaneous temperatures was considerable.

\section{Microhabitat Selection by Howlers}

When near-animal ambient temperatures were regressed on ambient temperature measured at other locations, all regression slopes were less than one (field: unstandardized $\beta=0.25 \pm 0.004, t_{3812}=58.0, P<0.001$; forest: $\beta=0.70 \pm 0.010, t_{3812}=72.1$,

Table III Top three multiple linear regression models for thermal variables impacting subcutaneous temperature of free-ranging mantled howling monkeys at La Pacifica, Costa Rica in 2014, selected using AIC

\begin{tabular}{llccrr}
\hline Model & Variable & Standardized $\beta$ & Standard error & $t$ & $P$-value \\
\hline 1 & Air temperature & 0.87 & 0.02 & 23.93 & $<0.001$ \\
& Solar radiation & -0.19 & $<0.01$ & -5.01 & $<0.001$ \\
& Vapor pressure & 0.04 & 0.01 & 1.67 & 0.095 \\
Wind speed & -0.05 & 0.09 & -2.38 & 0.017 \\
& Rain & -0.04 & 0.34 & -2.05 & 0.041 \\
& Air temperature & 0.88 & 0.01 & 24.53 & $<0.001$ \\
& Solar radiation & -0.19 & $<0.01$ & -5.15 & $<0.001$ \\
& Vapor pressure & 0.04 & 0.01 & 1.55 & 0.123 \\
Wind speed & -0.06 & 0.09 & -2.48 & 0.013 \\
& Air temperature & 0.88 & 0.01 & 24.29 & $<0.001$ \\
Solar radiation & -0.16 & $<0.01$ & -4.75 & $<0.001$ \\
& Wind speed & -0.06 & 0.09 & -2.97 & 0.003 \\
& Rain & -0.03 & 0.34 & -1.95 & 0.052 \\
\hline
\end{tabular}

For all models: $\mathrm{df}=1668$ 
$P<0.001$; weather station: $\beta=0.58 \pm 0.011, t_{3812}=58.0, P<0.001$ ) (Fig. 6). These effect sizes $(\beta)$ indicate that for each $1{ }^{\circ} \mathrm{C}$ increase in temperature measured at a stationary location, simultaneous near-animal ambient temperatures increased only $0.25-0.70{ }^{\circ} \mathrm{C}$ (Fig. 6). Likewise, at the coolest $25 \%$ of field and forest temperatures, near-animal ambient temperatures were warmer than the field $\left(\bar{x}\right.$ difference: $3.9{ }^{\circ} \mathrm{C}$, paired $t$-test: $t=50.7, P<0.001, \mathrm{df}=1,872)$ and forest measurements ( $\bar{x}$ difference: 3.1 ${ }^{\circ} \mathrm{C}, t=43.3, P<0.001$, df $\left.=1,886\right)$. In contrast, at the warmest $25 \%$ of field temperatures, near-animal ambient temperatures were cooler than the field by a mean difference of $7.5^{\circ} \mathrm{C}(t=-65.3, P<0.001, \mathrm{df}=1900)$, although this pattern did not hold true for the cooler forest temperature recordings $\left(\bar{x}\right.$ difference: $1.2{ }^{\circ} \mathrm{C}, t=20.9$, $P<0.001$, df $=1882$ ).
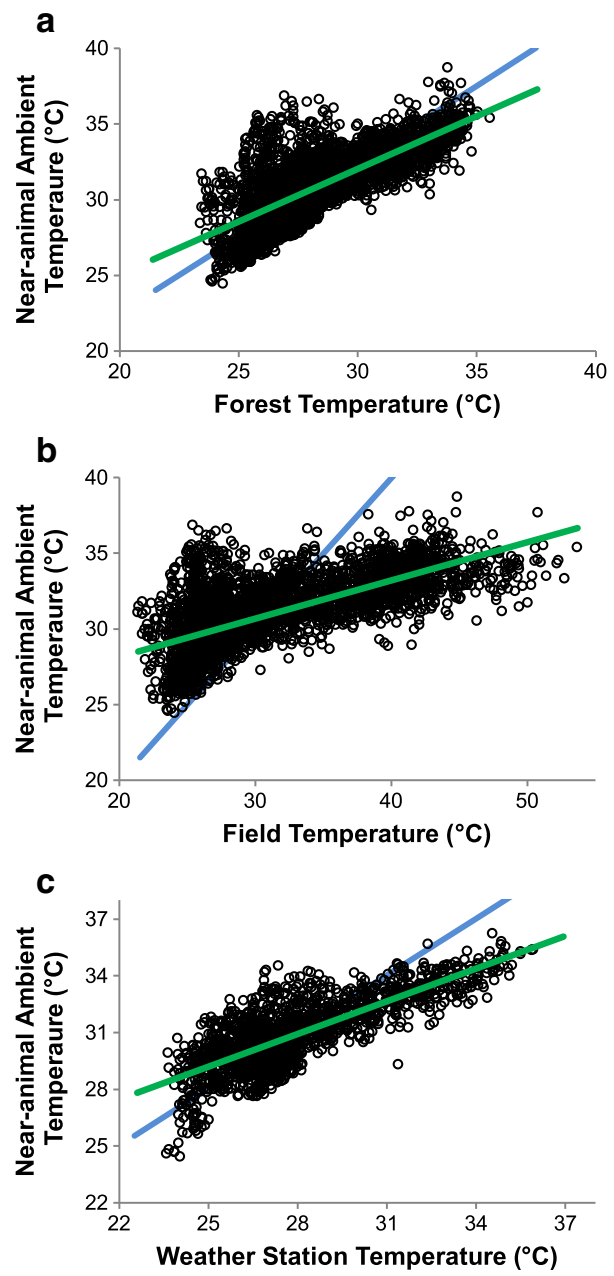

Fig. 6 Linear regressions between near-animal ambient temperatures from mantled howling monkeys and forest (a), field (b), and weather station (c) temperatures recorded at La Pacifica, Costa Rica in 2014. Green denotes the regression line; blue lines are derived from equations where the slope is $\beta=1$ and the $y$-intercept is the mean temperature difference between measurement locations (to account for overall location differences). 


\section{Discussion}

\section{Considerations for Temperature Measurement}

Our data demonstrate that ambient temperatures differed with measurement location at the study site. Although these data are specific to La Pacifica, the complexity of most primate habitats, and habitat use by primates, strongly suggests that future studies measuring ambient temperatures should consider methods that better reflect the immediate thermal environment animals experience. While some of the measurement locations examined in this study (e.g., open fields and on tree trunks near the ground) are frequently used as convenient places for researchers to collect temperature data, they are unlikely to reflect the range of thermal microhabitats available to arboreal primates. Temperature loggers located on animals will better reflect the temperature at their location as compared to stationary techniques. These on-animal data loggers are lightweight, relatively inexpensive, and easy to safely attach to animals, thus offering a promising tool for understanding thermal microhabitats used by primates.

There are further considerations to using these on-animal loggers. One concern is the potential for loggers to be impacted by animals' body heat. While radiant body heat can impact air temperatures near the skin, prior research has shown that for animals with minimal or no insulating fur (pigs and horses), air temperatures can reach ambient at a distance as little as $1.5 \mathrm{~cm}$ from the skin (Tregear 1965). Presumably this distance could be shorter in more densely furred animals where heat transmission is limited. Further, our analyses did not support the hypothesis that body temperatures influence near-animal ambient loggers. Notably, subcutaneous temperatures independently accounted for $<2 \%$ of variation in near-animal ambient temperatures. The correlation between subcutaneous and near-animal ambient temperatures was relatively lower compared to that between subcutaneous and other (stationary) ambient temperature measures, with near-animal ambient temperatures more often leading changes in subcutaneous temperatures rather than vice versa (Thompson et al. 2014). In addition, inconsistent correlations between day and nighttime demonstrate that body heat does not dictate the temperature recorded by near-animal ambient loggers. The daily waveforms of these temperatures (Fig. 3; Electronic Supplementary Material Fig. S1; Thompson et al. 2014: Fig. 1 and Supporting Information) further indicate that this lower correlation was not due to any fundamental differences in daily rhythm between near-animal ambient and subcutaneous temperatures. Instead, this lower correlation likely results from the inverse nature of body temperatures and microhabitat selection: when animals are warm, they should seek out relatively cooler microhabitats, and vice versa. Our analyses of microhabitat selection (discussed later) support this conclusion, showing that near-animal ambient temperatures were relatively lower than other measurements when ambient temperatures were high (Fig. 6). Similarly, our posture analysis did not support the prediction that body heat impacts loggers. Instead, our data suggest near-animal ambient temperatures reflect the ambient temperature at which postures are used for thermoregulatory purposes. While we cannot completely rule out any impact of body heat on loggers, the multiple lines of evidence above collectively indicate that animals' body heat did not markedly influence the results obtained from near-animal ambient loggers. 
In our data set, near-animal ambient temperatures often were warmer than forest temperatures. Given our finding that temperatures consistently increase with height in the forest canopy, this is not entirely surprising. It is worth noting that forest measurements, taken at $1 \mathrm{~m}$ off the ground on a tree trunk, reflect a habitat that howlers (mid- to upper-canopy users) rarely, if ever, use (pers. obs.). This is also an area more likely to be shaded, and hence cooler, than canopy heights actually inhabited by howlers. In fact, this reinforces a major finding from our data, that stationary temperature measurement locations common in primatological studies do not accurately reflect the thermal microhabitats used by animals.

Beyond impacts of body heat, additional logistic considerations remain for using onanimal loggers. First, animal capture/recapture is required, which may not be feasible for all sites or study species. Furthermore, while some models of these loggers can measure temperature and relative humidity, and hence vapor pressure, they cannot measure the full spectrum of thermal variables that impacted animals in this study (i.e., solar radiation, wind, and rain). In particular, solar radiation can influence the recorded temperature of these devices, and this was likely a significant source of higher temperatures in the field iButtons than the weather station (which is equipped with a solar radiation shield) in a similar setting. However, animals may be exposed to this solar radiation as well, which will influence their perception of temperature and, if exposed to sun, the temperature recorded by attached loggers. Pyranometers, which measure solar radiation directly, and black globe thermometers, which incorporate the influence of solar radiation when measuring heat stress (Hetem et al. 2007), are currently too large and protrusive to attach directly to primates, as well as withstand primates' highly manipulative nature. As such, the near-animal ambient temperature loggers in this study represent a trade-off for better location accuracy at the cost of measuring fewer thermal variables.

While weather stations are equipped to measure a range of thermal variables and can be useful for making gross-scale weather comparisons, they are less likely to reflect the microhabitat conditions directly experienced by primates. Most devices are recommended to be placed in a clearing away from trees and any rain, wind, or sun shadows (Onset 2015; Zachariassen et al. 2003) and as such likely yield better measures of a geographic area's overall climate rather than the microhabitat scale variation that directly influences primate behavior and physiology. If the goal of researchers is to better estimate the thermal environment of primates, stationary temperature measurement devices should be placed in locations that most closely replicate the target species' modal microhabitat (or possibly the high and low thermal extremes). Animals that exclusively use lower forest levels will likely be better represented by temperature measurements also taken under the canopy, whereas animals that frequently use exposed canopy tops might be better represented by measurements from a clearing.

Our finding that temperature measurements can vary over a small area $\left(<1 \mathrm{~km}^{2}\right)$ suggests that field sites that span diverse habitats should consider measuring temperature at multiple locations within the study area, at an average canopy height, or a range of canopy heights used by the target species. However, this approach will require deployment of several, relatively expensive and bulky weather stations. It is also worth noting that most weather stations are powered by solar-charged batteries (Onset 2015), meaning placements in forests pose significant challenges for keeping the battery charged, and placements under dense canopies may be entirely unfeasible. 
As an alternative, several environmental field studies have used large quantities (up to 175) of iButtons housed in solar shields to gather fine-scale temperature data across complex habitats (Ferreira-Ferreira et al. 2015; Holden et al. 2011). One drawback to this method, which also applies to this study, is the inclusion of between-logger error in temperature measurement. Despite this potential, iButtons and similar devices have yielded meaningful results and are becoming an increasingly common tool in environmental monitoring (Brabyn et al. 2014; Ferreira-Ferreira et al. 2015; Hester and Bauman 2013; Holden et al. 2011; Johnson et al. 2005; Lewkowicz 2008).

Taken collectively, near-animal loggers demonstrate a clear advantage for temperature measurements at the microhabitat scale, albeit at the sacrifice of a more comprehensive understanding of thermal variables. The use of both on-animal temperature loggers and more detailed thermal variables from (multiple) weather stations can improve measurement of the perceived thermal environment and help define operative temperatures, which control for radiation and convective heat transfer (Bakken et al. 1985), of arboreal primates.

\section{Microhabitat Selection by Howlers}

In addition to informing methodological considerations for characterizing primate microhabitats, our results also demonstrate that arboreal primates navigate a complex and dynamic thermal environment. Within this environment, the specific location in which temperatures are measured can yield substantially different values. Data from near-animal loggers indicate that howlers respond to thermal heterogeneity by selecting specific microhabitats. Animals appear to choose relatively warm microhabitats during cool nighttime hours and avoid warmer microhabitats (although they do not necessarily select the coolest areas) during hotter daytime temperature peaks (Figs. 3, 4, and 6). In particular, across all measurement locations near-animal ambient temperatures tended to be highest at night (Fig. 4a, c), also suggesting howlers select relatively warm locations at nighttime. While some of this may be selection by the animals, it may also be an artifact of our finding that temperatures increase with vertical height in the forest. This conclusion is behaviorally supported by data from a range of primates [chimpanzees (Pan troglodytes), titi monkeys (Callicebus nigrifrons), and red colobus monkeys (Piliocolobus badius)] documenting that animals spend more time in higher forest strata during cool periods and vice versa (Clutton-Brock 1973; Gestich et al. 2014; Takemoto 2004). This further supports the idea that temperatures measured closer to the ground (i.e., at researcher height) do not accurately represent the individual's immediate thermal environment. A similar finding was reported for terrestrial impalas (Aepyceros melampus), horses (Equus caballus), and wildebeests (Connochaetes taurinus), which rested in nighttime microhabitats with warmer temperatures than those recorded at weather stations (Hetem et al. 2007). The selection of warmer microhabitats at night concurs with previous research showing howlers at this site experience frequent cool thermal pressures at night (Thompson et al. 2014). There is also evidence that nocturnal temperatures drive body temperature in vervets (Chlorocebus pygerthrus: Lubbe et al. 2014), torpor bouts in fattailed dwarf lemurs (Cheirogaleus medius: Dausmann et al. 2005), and nest building in chimpanzees (Koops et al. 2012). This commonality of nighttime thermal pressures suggests that tropical primates may be more subject to cool thermoregulatory pressures than previously thought (Thompson et al. 2014). 


\section{Conclusions}

The complex spatial and temporal temperature patterns observed in this study, coupled with our evidence that howlers select specific thermal microhabitats, underscore a need for more fine-tuned thermal measurements of microhabitats used by primates. Stationary temperature measurements fail to capture these specific temporal changes in thermal microhabitats in a multidimensional arboreal landscape. Attaching automated temperature loggers directly to primates is a viable measurement alternative when animal capture is possible. The microhabitat data provided by these on-animal loggers can yield valuable insight into how arboreal primates navigate their thermally complex habitat.

Acknowledgments We thank Don Fernando Estrada and the Hacienda La Pacifica Board of Directors for permission to conduct research on their land. We also thank Mark Teaford for his extensive input on the manuscript, as well as Eduardo Fernandez-Duque and two anonymous reviewers for their helpful comments. P. Cofey, D. Mijatovic, E. Naylor, C. Scheidel, and J. Sidote provided assistance in the field. Ohio University and the Duke Arts and Sciences Council provided funding.

\section{References}

Agetsuma, N. (1995). Dietary selection by Yakushima macaques (Macaca fuscata yakui): the influence of food availability and temperature. International Journal of Primatology, 15(5), 611-627.

Bakken, G. S., Santee, W. R., \& Erskine, D. J. (1985). Operative and standard operative temperature: tools for thermal energetics studies. American Zoologist, 25(4), 933-943.

Baoping, R., Ming, L., Yongcheng, L., \& Fuwen, W. (2009). Influence of day length, ambient temperature, and seasonality on daily travel distance in the Yunnan snub-nosed monkey at Jinsichang, Yunnan, China. American Journal of Primatology, 71(3), 233-241.

Barradas, V., \& Fanjul, L. (1986). Microclimatic characterization of shaded and open-grown coffee (Coffea arabica) plantations in Mexico. Agricultural and Forest Meteorology, 38, 101-112.

Beehner, J. C., Onderdonk, D. A., Alberts, S. C., \& Altmann, J. (2006). The ecology of conception and pregnancy failure in wild baboons. Behavioral Ecology, 17(5), 741-750.

Bicca-Marques, J. C., \& Calegaro-Marques, C. (1998). Behavioral thermoregulation in a sexually and developmentally dichromatic Neotropical primate, the black-and-gold howling monkey (Alouatta caraya). American Journal of Physical Anthropology, 106(4), 533-546.

Brabyn, L., Zawar-Reza, P., Stichbury, G., Cary, C., Storey, B., et al. (2014). Accuracy assessment of land surface temperature retrievals from Landsat 7 ETM in the Dry Valleys of Antarctica using iButton temperature loggers and weather station data. Environmental Monitoring and Assessment, 186(4), 2619-2628.

Briscoe, N. J., Handasyde, K. A., Griffiths, S. R., Porter, W. P., Krockenberger, A., \& Kearney, M. R. (2014). Tree-hugging koalas demonstrate a novel thermoregulatory mechanism for arboreal mammals. Biology Letters, 10, 20140235.

Campos, F. A., \& Fedigan, L. M. (2009). Behavioral adaptations to heat stress and water scarcity in whitefaced capuchins (Cebus capucinus) in Santa Rosa National Park, Costa Rica. American Journal of Physical Anthropology, 138(1), 101-111.

Chiarello, A. G. (1995). Grooming in brown howler monkeys, Alouatta fusca. American Journal of Primatology, 35(1), 73-81.

Clutton-Brock, T. (1973). Feeding levels and feeding sites of red colobus (Colobus badius tephrosceles) in the Gombe National Park. Folia Primatologica, 19(5), 368-379.

Daubenmire, R. (1972). Phenology and other characteristics of tropical semi-deciduous forest in north-western Costa Rica. Journal of Ecology, 60(1), 147-170.

Dausmann, K. H. (2005). Measuring body temperature in the field-evaluation of external vs. implanted transmitters in a small mammal. Journal of Thermal Biology, 30(3), 195-202. 
Dausmann, K. H., Glos, J., Ganzhorn, J. U., \& Heldmaier, G. (2005). Hibernation in the tropics: lessons from a primate. Journal of Comparative Physiology B, 175(3), 147-155.

Dausmann, K., Glos, J., \& Heldmaier, G. (2009). Energetics of tropical hibernation. Journal of Comparative Physiology B, 179(3), 345-357.

De la Fuente, M. F. C., Souto, A., Sampaio, M. B., \& Schiel, N. (2014). Behavioral adjustments by a small Neotropical primate (Callithrix jacchus) in a semiarid caatinga environment. The Scientific World Journal, 2014, 326524.

Donati, G., Ricci, E., Baldi, N., Morelli, V., \& Borgognini-Tarli, S. M. (2011). Behavioral thermoregulation in a gregarious lemur, Eulemur collaris: effects of climatic and dietary-related factors. American Journal of Physical Anthropology, 144(3), 355-364.

Fedigan, L., \& Griffin, L. (1996). The Arashiyama West Japanese macaques. In J. E. Fa \& D. G. Lindburg (Eds.), Evolution and ecology of macaque societies (pp. 369-388). Cambridge: Cambridge University Press.

Fernandez-Duque, E. (2003). Influences of moonlight, ambient temperature, and food availability on the diurnal and nocturnal activity of owl monkeys (Aotus azarai). Behavioral Ecology and Sociobiology, 54(5), 431-440.

Ferreira-Ferreira, J., Silva, T. S. F., Streher, A. S., Affonso, A. G., Furtado, L. F. A., et al. (2015). Combining ALOS/PALSAR derived vegetation structure and inundation patterns to characterize major vegetation types in the Mamirauá Sustainable Development Reserve, Central Amazon floodplain, Brazil. Wetlands Ecology and Management, 23(1), 41-59.

Fetcher, N., Oberbauer, S., \& Strain, B. (1985). Vegetation effects on microclimate in lowland tropical forest in Costa Rica. International Journal of Biometeorology, 29(2), 145-155.

Gestich, C. C., Caselli, C. B., \& Setz, E. Z. (2014). Behavioural thermoregulation in a small Neotropical primate. Ethology, 120(4), 331-339.

Glander, K. E. (1975). Habitat description and resource utilization: a preliminary report on mantled howling monkey ecology. In R. H. Tuttle (Ed.), Socioecology and psychology of primates (pp. 37-57). The Hague: Mouton.

Glander, K. E., \& Nisbett, R. A. (1996). Community structure and species diversity in tropical forest associations at Hacienda La Pacifica in Guanacaste Province, Costa Rica. Brenesia, 45-46, 113-142.

Glander, K. E., Fedigan, L. M., Fedigan, L., \& Chapman, C. (1991). Field methods for capture and measurement of three monkey species in Costa Rica. Folia Primatologica, 57, 70-82.

Hanya, G. (2004). Seasonal variations in the activity budget of Japanese macaques in the coniferous forest of Yakushima: effects of food and temperature. American Journal of Primatology, 63(3), 165-177.

Hanya, G., Kiyono, M., \& Hayaishi, S. (2007). Behavioral thermoregulation of wild Japanese macaques: comparisons between two subpopulations. American Journal of Primatology, 69(7), 802-815.

Harrison, M. (1985). Time budget of the green monkey, Cercopithecus sabaeus: some optimal strategies. International Journal of Primatology, 6(4), 351-376.

Hester, E. T., \& Bauman, K. S. (2013). Stream and retention pond thermal response to heated summer runoff from urban impervious surfaces. Journal of the American Water Resources Association, 49(2), 328-342.

Hetem, R. S., Maloney, S. K., Fuller, A., Meyer, L. C., \& Mitchell, D. (2007). Validation of a biotelemetric technique, using ambulatory miniature black globe thermometers, to quantify thermoregulatory behaviour in ungulates. Journal of Experimental Zoology A, 307, 342-356.

Hill, R. A. (2006). Thermal constraints on activity scheduling and habitat choice in baboons. American Journal of Physical Anthropology, 129(2), 242-249.

Hill, R. A., Lycett, J. E., \& Dunbar, R. I. M. (2000). Ecological and social determinants of birth intervals in baboons. Behavioral Ecology, 11(5), 560-564.

Hill, R., Weingrill, T., Barrett, L., \& Henzi, S. P. (2004). Indices of environmental temperatures for primates in open habitats. Primates, 45(1), 7-13.

Holden, Z. A., Abatzoglou, J. T., Luce, C. H., \& Baggett, L. S. (2011). Empirical downscaling of daily minimum air temperature at very fine resolutions in complex terrain. Agricultural and Forest Meteorology, 151(8), 1066-1073.

Holdridge, L. M. (1967). Life zone ecology. San Jose: Tropical Science Center.

Johnson, G. S., \& Elizondo, R. S. (1979). Thermoregulation in Macaca mulatta: a thermal balance study. Journal of Applied Physiology, 46(2), 268-277.

Johnson, A. N., Boer, B. R., Woessner, W. W., Stanford, J. A., Poole, G. C., et al. (2005). Evaluation of an inexpensive small-diameter temperature logger for documenting ground water-river interactions. Groundwater Monitoring \& Remediation, 25(4), 68-74.

Kira, T., \& Yoda, K. (1989). Vertical stratification in microclimate. In H. Leith \& M. J. A. Werger (Eds.), Tropical rain forest ecosystems. Ecosystems of the world 14b. New York: Elsevier. 
Koops, K., McGrew, W. C., de Vries, H., \& Matsuzawa, T. (2012). Nest-building by chimpanzees (Pan troglodytes verus) at Seringbara, Nimba Mountains: antipredation, thermoregulation, and antivector hypotheses. International Journal of Primatology, 33(2), 356-380.

Lewkowicz, A. G. (2008). Evaluation of miniature temperature-loggers to monitor snowpack evolution at mountain permafrost sites, northwestern Canada. Permafrost and Periglacial Processes, 19(3), 323-331.

Limberger, D., Trillmich, F., Biebach, H., \& Stevenson, R. D. (1986). Temperature regulation and microhabitat choice by free-ranging Galapagos fur seal pups (Arctocephalus galapagoensis). Oecologia, 69(1), 53-59.

Lopez, K. R., Gibbs, P. H., \& Reed, D. S. (2002). A comparison of body temperature changes due to the administration of ketamine-acepromazine and tiletamine-zolazepam anesthetics in cynomolgus macaques. Journal of the American Association for Laboratory Animal Science, 41(2), 47-50.

Lovegrove, B. (2009). Modification and miniaturization of Thermochron iButtons for surgical implantation into small animals. Journal of Comparative Physiology B, 179(4), 451-458.

Lubbe, A., Hetem, R. S., McFarland, R., Barrett, L., Henzi, P., et al. (2014). Thermoregulatory plasticity in freeranging vervet monkeys, Chlorocebus pygerythrus. Journal of Comparative Physiology B, 184, 799-809.

Mabille, G., Berteaux, D., Thomas, D. W., \& Fortin, D. (2011). Behavioural responses of wintering porcupines to their heterogeneous thermal environment. Ecoscience, 18(4), 341-353.

Martin, P., \& Bateson, P. (1993). Measuring behavior: An introductory guide (2nd ed.). Cambridge: Cambridge University Press.

McFarland, R., Barrett, L., Boner, R., Freeman, N. J., \& Henzi, S. P. (2014). Behavioral flexibility of vervet monkeys in response to climatic and social variability. American Journal of Physical Anthropology, 154(3), 357-364.

McFarland, R., Fuller, A., Hetem, R. S., Mitchell, D., Maloney, S. K., et al. (2015). Social integration confers thermal benefits in a gregarious primate. Journal of Animal Ecology, 84(3), 871-878.

Müller, E. F. (1979). Energy metabolism, thermoregulation and water budget in the slow loris (Nycticebus coucang, Boddaert 1785). Comparative Biochemistry and Physiology. Part A, Physiology, 64(1), 109-119.

Nowack, J., Wippich, M., Mzilikazi, N., \& Dausmann, K. H. (2013). Surviving the cold, dry period in Africa: behavioral adjustments as an alternative to heterothermy in the African lesser bushbaby (Galago moholi). International Journal of Primatology, 34(1), 49-64.

Ohsawa, H., \& Dunbar, R. I. M. (1984). Variations in the demographic structure and dynamics of gelada baboon populations. Behavioral Ecology and Sociobiology, 15(3), 231-240.

Onset. (2015). Deploying weather stations: a best practices guide. Bourne: Onset Computer Corporation.

Pinker, R. (1980). The microclimate of a dry tropical forest. Agricultural Meteorology, 22(3), 249-265.

Pörtner, H. O., Bennett, A. F., Bozinovic, F., Clarke, A., Lardies, M. A., et al. (2006). Trade-offs in thermal adaptation: the need for a molecular to ecological integration. Physiological and Biochemical Zoology, 79(2), 295-313.

Pruetz, J. (2007). Evidence of cave use by savanna chimpanzees (Pan troglodytes verus) at Fongoli, Senegal: implications for thermoregulatory behavior. Primates, 48(4), 316-319.

Raichlen, D. A., Gordon, A. D., Muchlinski, M. N., \& Snodgrass, J. J. (2010). Causes and significance of variation in mammalian basal metabolism. Journal of Comparative Physiology B, 180(2), 301-311.

Refinetti, R. (2010). The circadian rhythm of body temperature. Frontiers in Bioscience: A Journal and Virtual Library, 15, 564-594.

Shi, H., Paull, D., Broome, L., \& Bates, H. (2015). Microhabitat use by mountain pygmy-possum (Burramys parvus): implications for the conservation of small mammals in alpine environments. Austral Ecology, 40(5), 528-536.

Stitt, J. T., \& Hardy, J. D. (1971). Thermoregulation in the squirrel monkey (Saimiri sciureus). Journal of Applied Physiology, 31(1), 48-54.

Takemoto, H. (2004). Seasonal change in terrestriality of chimpanzees in relation to microclimate in the tropical forest. American Journal of Physical Anthropology, 124(1), 81-92.

Terrien, J., Perret, M., \& Aujard, F. (2011). Behavioral thermoregulation in mammals: a review. Frontiers in Bioscience: A Journal and Virtual Library, 16, 1428-1444.

Thompson, C. L., Williams, S. H., Glander, K. E., Teaford, M. F., \& Vinyard, C. J. (2014). Body temperature and thermal environment in a generalized arboreal anthropoid, wild mantled howling monkeys (Alouatta palliata). American Journal of Physical Anthropology, 154, 1-10.

Tregear, R. T. (1965). Hair density, wind speed, and heat loss in mammals. Journal of Applied Physiology, 20(4), 796-801.

van Schaik, C. P., \& Pfannes, K. R. (2005). Tropical climates and phenology: a primate perspective. In D. K. Brockman \& C. P. van Schaik (Eds.), Seasonality in primates: studies of living and extinct human and non-human primates (pp. 23-54). Cambridge: Cambridge University Press. 
Zachariassen, J., Zeller, K., Nikolov, N., \& McClelland, T. (2003). A review of the forest service remote automated weather station (RAWS) network. United States Department of Agriculture, Forest Service, General Technical Report RMRS-GTR-119.

Zajicek, K. B., Price, C. S., Shoaf, S. E., Mehlman, P. T., Suomi, S. J., et al. (2000). Seasonal variation in CSF 5-HIAA concentrations in male rhesus macaques. Neuropsychopharmacology, 22(3), 240-250. 